\title{
Land subsidence monitoring using distributed fiber optic sensing with Brillouin scattering in coastal and deltaic regions
}

\author{
Kai Gu${ }^{1}$, Su-Ping Liu ${ }^{1}$, Bin Shi ${ }^{1}$, Yi Lu ${ }^{2}$, and Yue-Hua Jiang ${ }^{3}$ \\ ${ }^{1}$ School of Earth Sciences and Engineering, Nanjing University, Nanjing 210023, China \\ ${ }^{2}$ Key Laboratory of Earth Fissures Geological Disaster, Ministry of Land and Resources \\ (Geological Survey of Jiangsu Province), Nanjing 210018, China \\ ${ }^{3}$ Nanjing Center, China Geological Survey, Nanjing 210016, China \\ Correspondence: Kai Gu (gukai@nju.edu.cn) and Bin Shi (shibin@nju.edu.cn)
}

Published: 22 April 2020

\begin{abstract}
Excessive withdrawal of groundwater in coastal and deltaic regions is one of the main reasons which induce land subsidence in these areas. Land surface displacement monitoring with conventional methods is not able to pinpoint subsurface compacting, which is very challenging. Instead of groups of extensometers, we apply distributed fiber optic sensing (DFOS) with Brillouin scattering in vertical boreholes to identify the deformation distribution along the entire borehole with meter-scale spatial resolution. We here present 10 boreholes with depths range from 100 to $600 \mathrm{~m}$ with DFOS monitoring along the east coastal line of Jiangsu and Shanghai since 2015, and 1 borehole of $300 \mathrm{~m}$ in depth in Yangtze River delta since 2012. The results provide clear images on the deformation distribution along entire boreholes, by identifying the main contributors to the subsidence and the deformation evolutionary processes, with stable long-term monitoring performance. Hence, we demonstrate that DFOS can open window into subsurface deformation and could be important complementary to conventional methods to understand the land subsidence processes in coastal and deltaic regions.
\end{abstract}

\section{Introduction}

Land subsidence due to anthropogenic groundwater withdrawal combined with a global sea level rise creates serious environmental problems in the coastal and deltaic regions, including differential subsidence and infrastructure damage, elevation decrease, increased vulnerability to flooding and tsunami, and permanent inundation of lowland (Higgins, 2016). In China, there have been 102 cities suffering from land subsidence by 2015. Cities in coastal and deltaic regions account a large proportion in those subsiding cities due to large population and high demand in groundwater. The pursuit of effective mitigation of subsidence, long term urban planning and others have driven the demand of sufficient observation of land subsidence. However, in general, the complex aquifer systems in coastal and deltaic regions may pose great challenges to identify the subsurface deformations when the compacting is inhomogeneous.
Ground-based techniques (including leveling, extensometers, GPS and T-LiDAR) and space-based techniques (including InSAR and LiDAR) are currently the main techniques used for land subsidence monitoring (Bürgmann et al., 2000; Galloway and Burbey, 2011; González and Fernández, 2011). Most of these techniques obtain the surface displacements while groups of borehole extensometers can obtain subsurface deformation (Lofgren, 1969; Riley, 1986), but only measures limited strata deformation due to the construction and cost issues.

More recently, a novel method to monitor land subsidence using distributed optical fiber sensing (DFOS) with Brillouin scattering has been developed. DFOS enables the monitoring of strain along the entire optical fiber with continuous spatial measurements therefore the deformation along the optical fiber can be obtained. The feasibility of DFOS in vertical boreholes for land subsidence monitoring has been illustrated by Gu et al. (2018), Wu et al. (2015) and Zhang et al. (2018) 


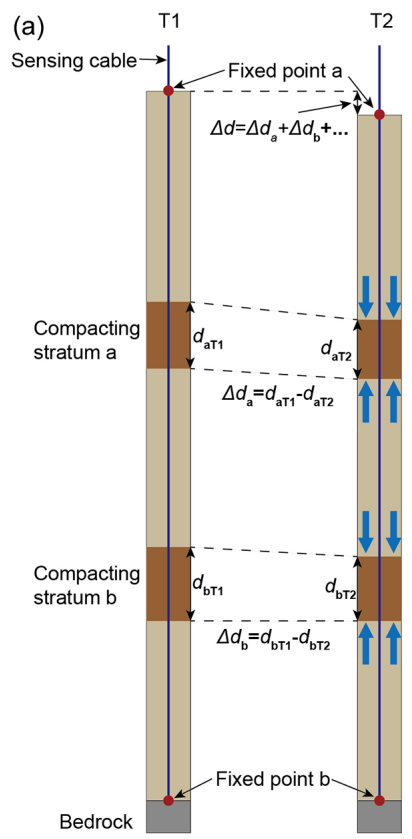

(b)

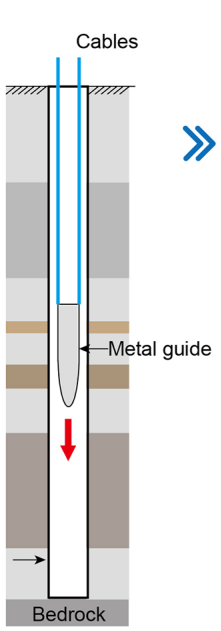

(i)

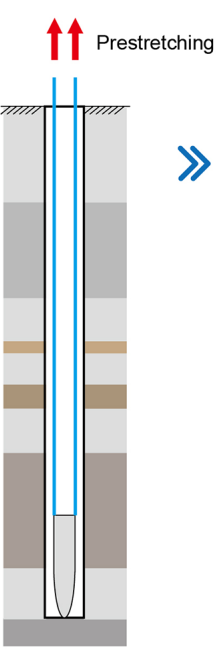

(ii)

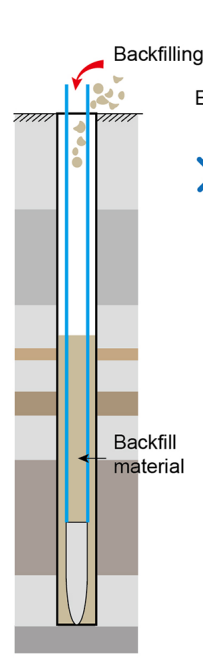

(iii)

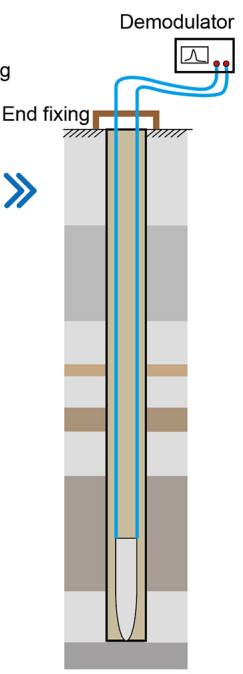

(iv)

*Not to scale

Figure 1. (a) The idea of land subsidence monitoring using DFOS, $d$ : thickness of a stratum; T1 \& T2: time of data acquisition. (b) The procedure of the cable installation (cable insert $\rightarrow$ cable prestretching $\rightarrow$ backfilling with standard materials $\rightarrow$ end fixing) (Modified from Gu et al., 2020).

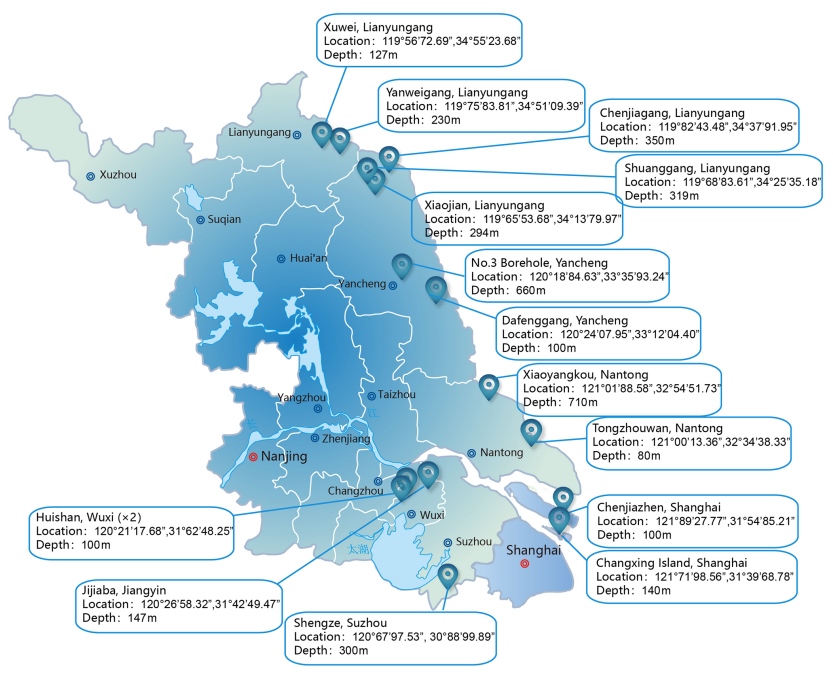

Figure 2. The locations of land subsidence monitoring boreholes using DFOS in Jiangsu and Shanghai.

and their results indicated that the ability of DFOS in obtaining continuous strata deformation offers a good option in monitoring the deformations of soft soils in coastal and deltaic regions.

In this paper, we introduce the monitoring of land subsidence using DFOS in coastal and deltaic regions, including the general idea and the key techniques. Additionally, the boreholes we set up in coastal and deltaic regions located in Jiangsu and Shanghai were presented.

\section{Land subsidence monitoring using DFOS}

By installing slender sensing cables into a vertical borehole (Fig.1a), the strata deformation along the entire borehole can be obtained according to the frequency changes measured by the cable. Among other DFOS techniques, Brillouin scattering such as Brillouin Optical Time Domain Reflectometer (BOTDR) is employed. The frequency shifts of Brillouin scattering have linear correlations to the changes of longitudinal strain and temperature (Bao and Chen, 2011). It is notable that the negative strains of the sensing cable indicate the compression of strata while the positive strains indicate the rebound of strata. A typical spatial resolution and measurement accuracy of BOTDR is $1 \mathrm{~m}$ and $50 \mu \varepsilon$, respectively.

Figure $1 \mathrm{~b}$ illustrated the procedure of the cable installation. According to the installation method, this novel method only measures the vertical displacement. The fixed point on the bedrock is immobile and the sensing cables should be kept in tension and straight during the entire monitoring period.

\section{Key issues of the method}

Generally, there are three key issues that should be carefully consideration for the application of DFOS in the land subsidence monitoring: (1) suitable sensing cables; (2) backfill 

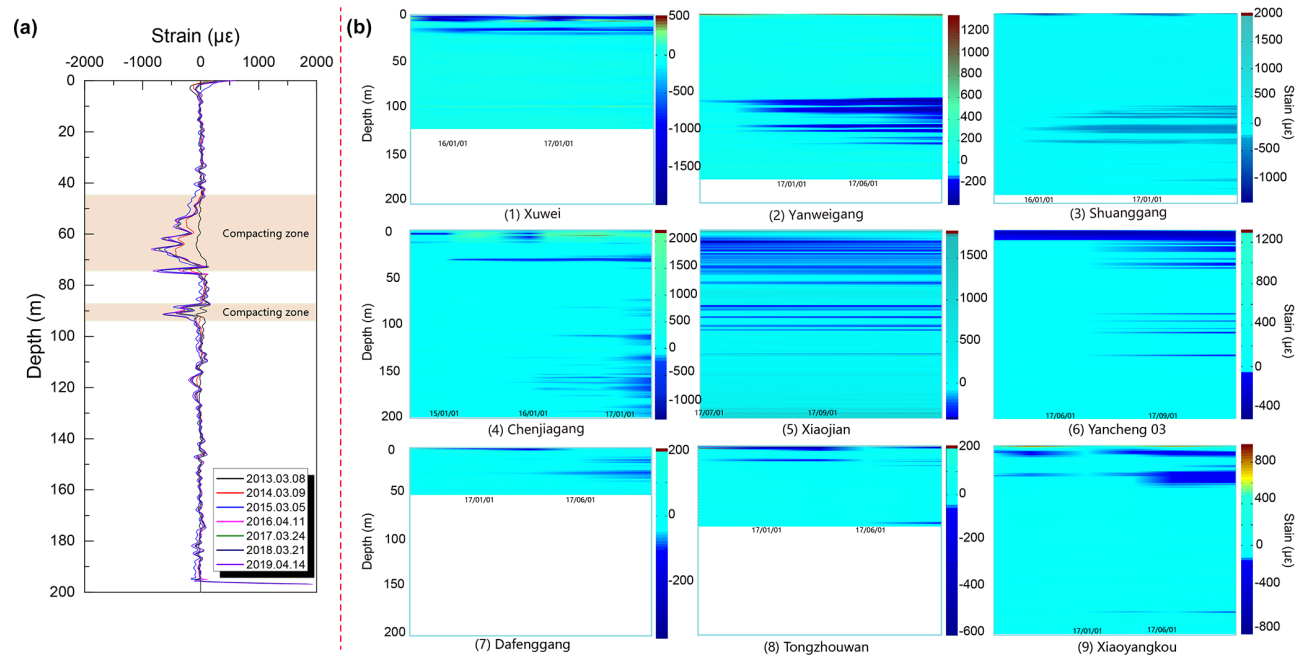

Figure 3. The subsurface deformation obtained by DFOS. (a) Typical strain distribution along the borehole, (b) Subsurface deformations in boreholes in the coastal region.

materials and (3) the coupling behavior between cables and surrounding soils.

The complex subsurface conditions and the cable installation process require strong but sensitive sensing cables. Therefore, two sensing cables namely metal-reinforced cable (MRC) and fix-point cable (FPC) were developed. The structures of these two cables were introduced by Wu et al. (2015). The backfill materials are very critical for the coupling of sensing cable and surrounding soils, eventually for the validity of monitoring results. Undisturbed soils would be ideal borehole backfill materials while it is impractical. The selection of backfill materials concerns the complexity of the backfilling (e.g. the use of clay may jam boreholes) and the engineering properties of the backfill materials (e.g. the coefficient of compressibility, etc.). We use a mixture of sand and gravel, whose $d_{60}, d_{30}$, and $d_{10}$ is $0.74,0.30$ and $0.12 \mathrm{~mm}$, respectively, with the coefficient of uniformity $\left(C_{\mathrm{u}}\right)$ of 6.33 and the coefficient of curvature $\left(C_{\mathrm{c}}\right)$ of 1.09 . Such well-graded backfill material can be smoothly backfilled without jamming the borehole. The previous study indicated that the horizontal confining pressure is the principle factor that affect the coupling behavior of sensing cable and soils. The critical depth below which is considered to have strong coupling is generally smaller than $40 \mathrm{~m}$, depending on the type of the soils. Since the boreholes for subsidence monitoring are usually deeper than $100 \mathrm{~m}$, such critical depth should be acceptable. Additionally, backfill materials are found to have insignificant impact on the coupling as long as the confining pressure is large enough.

\section{Preliminary monitoring network using DFOS in coastal and deltaic regions}

Since 2012, 15 land subsidence monitoring boreholes using DFOS have been set up in coastal and deltaic regions. Among them, 9 boreholes are in coastal region (east coast of Jiangsu, China) and 6 boreholes are in the low Yangtze River delta (south Jiangsu and Shanghai). The borehole locations are given in Fig. 2. The data acquisition is conducted every 2-4 months so the seasonal variation of strata deformations can be recorded. The depth of borehole is usually more than $100 \mathrm{~m}$ and the deepest borehole is up to $710 \mathrm{~m}$.

\section{Results}

Figure 3a shows the typical results obtained by DFOS (i.e. relative strain variation after subtracting the initial strain distribution). The deformation of strata induced the strain variation and the continuous strain distribution along the entire borehole clearly identified the compacting strata. The detailed results also provide the temporal and spatial characteristics of the subsurface deformation. Figure $3 b$ give the preliminary results based on MRC obtained in the boreholes located in the coastal regions. As can be seen that the subsurface deformation is quite inhomogeneous and some compacting may occur within very thin layers. The precise depths of deformation offer a clear image of the subsidence process and important information on the understanding of the subsidence mechanisms. The comparison between DFOS result and that obtained by conventional method was conducted in the Shengze borehole since 2015, and a very good consistency in subsiding rate and trend was observed ( $\mathrm{Gu}$ et al., 2020), although such comparison was limited so far. Further comparison between DFOS and other methods including ex- 
tensometers and InSAR is now in process and will be reported in our future work.

\section{Conclusions}

It is challenging to monitoring the subsurface deformations in coastal and deltaic regions. Distributed fiber optic sensing (DFOS) provides "neuro" (i.e. sensing cables) to the subsurface and can open a window into subsurface deformation. The detailed results on the deformation allow us to precisely locate the compacting strata and better understand the subsurface deformation with temporal and spatial characteristics. A preliminary monitoring network using DFOS has been set up in east and south Jiangsu and Shanghai, China, including 15 boreholes and has been providing detailed subsurface deformation along those boreholes. It is foreseeable that DFOS has very good potential in land subsidence monitoring in coastal and deltaic regions, although further improvement on this novel method is still required.

Data availability. Some or all data, models, or code generated or used during the study are available from the corresponding author by request.

Author contributions. KG proposed the method, conducted the field tests, analyzed the data and prepared the manuscript. SPL conducted the field tests and analyzed the data. BS proposed the method and reviewed the manuscript. YL and YHJ provided the sites and the critical field data and reviewed the manuscript.

Competing interests. The authors declare that they have no conflict of interest.

Special issue statement. This article is part of the special issue "TISOLS: the Tenth International Symposium On Land Subsidence - living with subsidence". It is a result of the Tenth International Symposium on Land Subsidence, Delft, the Netherlands, 17-21 May 2021.

Acknowledgements. We thank Guang-Qing Wei from Suzhou NanZee Sensing Ltd., China for providing the field assistance.

Financial support. This research has been supported by the National Natural Science Foundation of China (grant nos. 41427801, 41502274, 41977217), the Key Project of Nanjing University Technology Innovation Fund (grant no. SC-2019-101), and the China Geological Survey Program (grant no. DD20190260).

\section{References}

Bao, X. and Chen, L.: Recent Progress in Brillouin Scattering Based Fiber Sensors, Sensors, 11, 4152-4187, https://doi.org/10.3390/s110404152, 2011.

Bürgmann, R., Rosen, P. A., and Fielding, E. J.: Synthetic Aperture Radar Interferometry to Measure Earth's Surface Topography and Its Deformation, Annu. Rev. Earth Planet. Sci., 28, 169209, https://doi.org/10.1146/annurev.earth.28.1.169, 2000.

Galloway, D. L. and Burbey, T. J.: Review: Regional land subsidence accompanying groundwater extraction, Hydrogeol. J., 19, 1459-1486, https://doi.org/10.1007/s10040-011-0775-5, 2011.

González, P. J. and Fernández, J.: Drought-driven transient aquifer compaction imaged using multitemporal satellite radar interferometry, Geology, 39, 551-554, https://doi.org/10.1130/G31900.1, 2011.

Gu, K., Shi, B., Liu, C., Jiang, H., Li, T., and Wu, J.: Investigation of land subsidence with the combination of distributed fiber optic sensing techniques and microstructure analysis of soils, Eng. Geol., 240, 34-47, https://doi.org/10.1016/j.enggeo.2018.04.004, 2018.

Gu, K., Shi, B., Wu, J. H., Zhang, C. C., Liu, S. P., Jiang, H. T., Lu, Y., and Jiang, Y. H.: An insight into land subsidence using distributed fiber optic sensing with Brillouin scattering and a 6.5year case in Yangtze River delta, J. Geophys. Res.-Earth Surf., submitted, 2020.

Higgins, S. A.: Review: Advances in delta-subsidence research using satellite methods, 24, 587-600, https://doi.org/10.1007/s10040-015-1330-6, 2016.

Lofgren, B. E.: Field measurement of aquifer-system compaction, San Joaquin Valley, California, U.S.A, in: Land subsidence, Proceedings of the Tokyo Symposium, edited by: Tison, L. J., Sept 1969, IAHS Publ. 88, 272-284, 1969.

Riley, F. S.: Developments in borehole extensometry, in: Land subsidence, Proceedings of the Third International Symposium on Land Subsidence, edited by: Johnson, A. I., Carbognin, L., and Ubertini, L., Venice, Italy, March 1984, IAHS Pub. 151, 169 186, 1986.

Wu, J., Jiang, H., Su, J., Shi, B., Jiang, Y., and Gu, K.: Application of distributed fiber optic sensing technique in land subsidence monitoring, J. Civil Struct. Health Monit., 5, 587-597, https://doi.org/10.1007/s13349-015-0133-8, 2015.

Zhang, C. C., Shi, B., Gu, K., Liu, S. P., Wu, J. H., Zhang, S., Zhang, L., Jiang, H. T., and Wei, G. Q: Vertically Distributed Sensing of Deformation Using Fiber Optic Sensing, Geophys. Res. Lett., 45, 11732-11741, https://doi.org/10.1029/2018GL080428, 2018. 